\title{
Space as a Resource in Creative Design Practices
}

\author{
Dhaval Vyas ${ }^{1}$, Gerrit van der Veer ${ }^{2}$, Dirk Heylen ${ }^{1}$, and Anton Nijholt ${ }^{1}$ \\ ${ }^{1}$ Human Media Interaction, University of Twente, The Netherlands \\ ${ }^{2}$ School of Computer Science, Open University, The Netherlands \\ d.m.vyas@ewi.utwente.nl
}

\begin{abstract}
Based on longitudinal ethnographic fieldwork in two industrial design departments and two design companies, we explore the role of spatial arrangements for supporting creative design practices within different design studios. From our results, we show that designers explicitly make use of the physical space for 1) communicating and inspiring design ideas, 2) exploring design solutions and 3) managing design projects. We believe that these design practices could bring insightful implications for developing ubiquitous technologies to support the design profession.
\end{abstract}

Keywords: Workspace, design practice, ethnography, creativity.

\section{Introduction}

The spatial aspects of design studios play an important role in supporting different design activities, techniques and use of material and digital tools. Within a typical design studio, desks, office walls, clipboards, drawing boards and so on are full of informative, inspirational and creative design-related artefacts such as handmade sketches, drawings, posters, post-it notes, physical models, prototypes and the like. This kind of information can be seen as external representations of the ongoing design activities. The physical space within design studios is not just a carrier for designrelated information but importantly it is a site of methodic design practices. The space offers resources for social, organizational and individual activity [3] that designers routinely encounter and use on an everyday basis.

Conceptual frameworks such as Distributed Cognition [2] and Organizational Memory [1] suggest that information about a particular work setting or a work culture is distributed between different external representations and people situated there. In a domain such as design, where the whole design process progresses through different multimodal information (from handmade sketches to final prototypes), the study of spatial arrangement becomes an important issue.

We studied two industrial design departments and two design companies over a period of 8 months. We used an ethnomethodologically-informed ethnographic approach [4] to understand designers' practices in their natural settings and to get an insight into the approaches and methods they use in going about their everyday work. We used three methods: 1) contextual interviews, 2) naturalistic observations, and 3) recorded design sessions of design students and professionals. In this paper, we organize our results focusing on the spatial aspects and show that designers explicitly make use of the physical space for the purpose of communicating and inspiring design 
ideas, exploring design solutions and managing design projects. We believe that in order to better support designers' work and to develop ubiquitous collaborative technologies, we need to understand how spatial aspects support cooperative practices of designers' and what role they play in supporting creativity in the everyday work.

\section{Use of Space in Cooperative Design}

In our study we observed that physical space within design studios supports 'explorative' and 'coordinative' activities amongst co-designers. Focusing on the creative use of physical space, we provide our results in three themes: communicating and inspiring design ideas, exploring design solutions and managing design projects.

Communicating and inspiring design ideas. Designers keep sketches, drawings, pictures, design models and other relevant things on their working space and surfaces such as clipboards, drawing boards and office walls in a way that constantly informs and inspires their design work (figure 1). The multimodality and ability to support and convey information through multiple senses facilitate rich communications between co-workers. Additionally, the design artefacts that are attached to particular spatial objects are indicative of different phases of the design process, the current state, future planning, and so on. One designer commented, "depending on the phase of the project, I arrange my surroundings. It's important for me to have these artefacts around so that I can register where I am at in the project'. So, these design artefacts are also reminders.

The construction of these evocative workplaces is also intended to develop new ideas, inspiration and creative thinking. One designer commented, "Normally within a project I need a strong foundation to start with. So, when I am communicating my ideas I need to have several different aspects about my design. Because when the foundation is strong it helps in convincing people. These visual objects around me show my foundational work and work as strong building blocks."

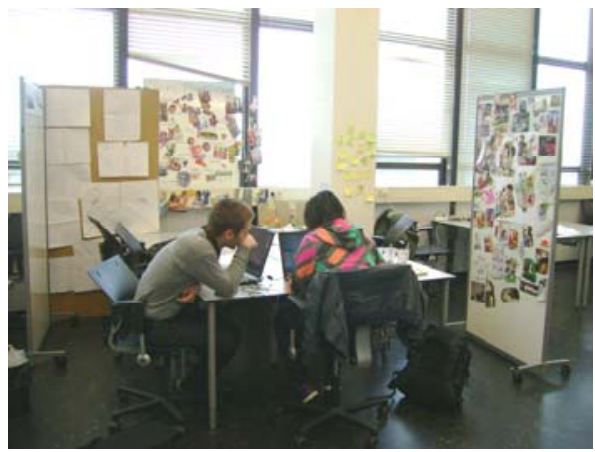

Fig. 1. A section of a design studio where design students have utilized different surfaces to support design work

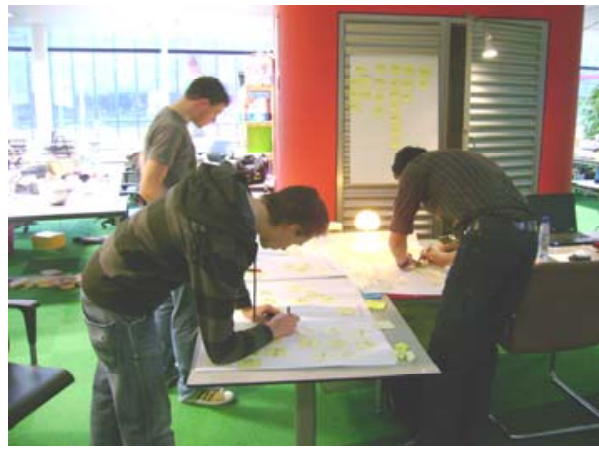

Fig. 2. An example where a group of design students are brainstorming on an ephemeral workspace 
Another important aspect of utilizing space to support design activities is to experiment with the physical space in order to develop a creative ecology within design studios. As can be seen in figure 2, designers have created an ephemeral workspace where they can brainstorm and collect or develop new design ideas for their ongoing projects. In some cases the students would intentionally move around, change location of their working, create new collaborative spaces, play with different things in the studio, and so on.

Exploring design solutions. Another reason to utilize space is to explore design solutions by elaborating and/or dividing design challenges in order to generate detailed descriptions and related aspects. This in turn would help in resolving a particular design situation. The way physical space allows the representation of design tasks can affect designers' reasoning abilities and performance. As one designer suggested, "I normally try to visualize all the material and data that I collected from my user studies and try to find out patterns and explore design opportunities from this data. I then make my own sketches and models and keep all these in a way that can help me find out new ideas". Several examples of this were seen in both of the design studios. Designers keep, for example, pictures from ethnographic or other field studies on their office walls and on their desks (figure 3). The aim here is not just to solve a design problem but to collect greater and useful insights of a given situation so that a solution can be envisioned.

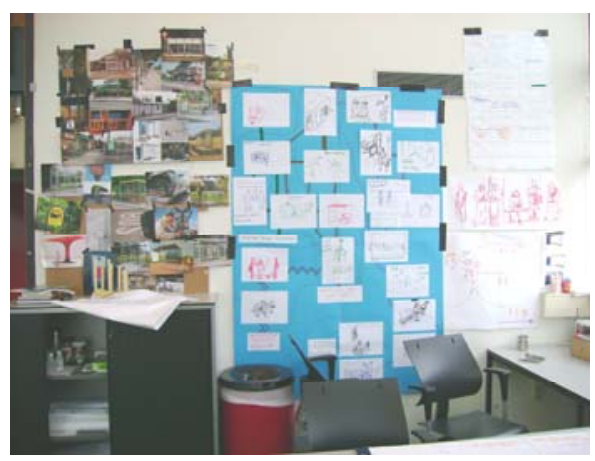

Fig. 3. An example where an office wall is used to elaborate a design problem, by arranging and connecting images from field studies and design sketches

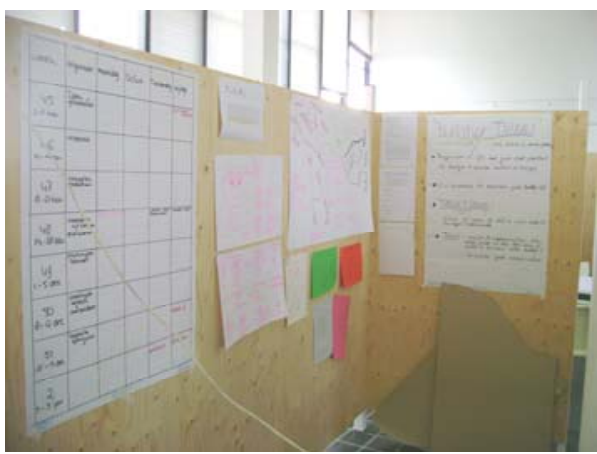

Fig. 4. An example where a group of designers have devised physical space to keep project-specific information

Managing design projects. Design being a collaborative process requires organization and management of the work of co-designers. The spatial aspects within design studios also play a role in supporting organization and management of design projects. Figure 4 shows an example where a design team has used wooden panels, and movable drawing boards to store information related to detailed project descriptions, project plan, data generated from brainstorming sessions, design concepts, work division within a team and to-do lists. Each individual piece of design-related information has a strong even explicit link to some aspect of the project at hand. The ecology of 
these pieces of information creates an information rich environment needed to stimulate creativity and to develop novel ideas.

Within an ongoing design project, designers deal with a plethora of design materials, and being aware of different 'happenings' is an important issue. We observed that the way designers keep project-related design materials on different spatial objects within their studios improves the visibility and provides an overview of the work being carried out. Understanding how design artefacts within a work environment are organized, configured, manipulated and handled supports the awareness of co-workers' activities and, hence, contributes to the coordination of work. Design iterations, methods, and conventions can be easily extracted when design artefacts and related materials are kept in public visibility using physical space. The visibility of design activities is also manifested in and through the use of these artefacts. At the same time such a creative space could provide opportunities to reflect on the ongoing project and to allow designers to change, combine or divert aspects of their design process.

\section{Conclusions and Future Work}

What has been presented here is an account of how space is used to support creative design practices by designers in the academic as well as the professional domains. As we observed, the physical space within a design studio offer resources that range from clearly defining design problems, exploring new possibilities and easing communicative difficulties to developing a communication language with co-workers.

Creativity is a critical aspect of design and needs to be supported though technological means. We believe that an account of real-world design practices such as this could be very fruitful if we are to design collaborative technologies. Within an ongoing research project, we are investigating other aspects related to collaborative design practices (e.g. [5]). We plan to combine the results of these ethnographic studies and develop implications for designing collaborative technologies. We also plan to develop a system to be tested in real-world design practices.

Acknowledgements. This work is supported by the EU Project AMIDA (FP60033812).

\section{References}

1. Ackerman, M.S., Halverson, C.: Organizational Memory: Processes, Boundary Objects, and Trajectories. In: Proc. of the 32nd Annual Hawaii international Conference on System Sciences. HICSS, vol. 1. IEEE Computer Society, Washington (1999)

2. Hutchins, E.: Cognition in the wild. MIT Press, Cambridge (1995)

3. Perry, M., O’Hara, K.: Display-Based Activity in the Workplace. In: Rauterberg, M., et al. (eds.) Proc. of INTERACT 2003. IFIP, pp. 591-598. IOS Press, Amsterdam (2003)

4. Randall, D., Harper, H., Rouncefield, M.: Fieldwork for Design - Theory and Practice. CSCW series. Springer, London (2007)

5. Vyas, D., Heylen, D., Nijholt, A.: Physicality and Cooperative Design. In: Popescu-Belis, A., Stiefelhagen, R. (eds.) MLMI 2008. LNCS, vol. 5237, pp. 325-337. Springer, Heidelberg (2008) 